\title{
BIOTRANSFORMAÇÃO DE LIMONENO: UMA REVISÃO DAS PRINCIPAIS ROTAS METABÓLICAS
}

\author{
Mário Roberto Maróstica Júnior* e Gláucia Maria Pastore \\ Departamento de Ciência de Alimentos, Faculdade de Engenharia de Alimentos, Universidade Estadual de Campinas, CP 6121, \\ 13083-970 Campinas - SP, Brasil
}

Recebido em 11/8/05; aceito em 20/4/06; publicado na web em 24/10/06

\begin{abstract}
BIOTRANSFORMATION OF LIMONENE: A REVIEW OF THE MAIN METABOLIC PATHWAYS. There is considerable progress in the study of the biotransformation of limonene. Extensive research on the biotransformation of limonene has resulted in the elucidation of new metabolic pathways. Natural flavors can be produced via biotransformation, satisfying consumer demand for natural products. This review presents some elements concerning the biotransformation of limonene with emphasis on the metabolic pathways. Some comments are also made on problems related to biocatalysis as well as on the application of some compounds originating from the biotransformation of the inexpensive limonene.
\end{abstract}

Keywords: limonene; biotransformation; pathways.

\section{INTRODUÇÃO}

Nos últimos anos, a produção biotecnológica de compostos de aroma vem sendo estimulada pela crescente demanda do mercado consumidor por produtos rotulados como "naturais" e "saudáveis"1. As legislações norte-americana e européia referem-se aos compostos de aroma naturais como aqueles preparados tanto por processos físicos (extração de suas fontes naturais) como por processos enzimáticos e microbianos que envolvem precursores isolados na natureza, sendo que o composto gerado deve ser idêntico ao já existente na natureza para que a substância seja legalmente rotulada como "natural'". Isso, aliado ao interesse por aromas naturais em vez de aromas sintéticos levou a um aumento de investigações focadas em produção biotecnológica dos denominados 'bioaromas'. A maioria dos compostos de aroma usados no mundo (aproximadamente $80 \%$ ) utiliza processos químicos para sua obtenção. Entretanto, observa-se uma nova tendência em países desenvolvidos, como a Alemanha, onde $70 \%$ de todos os compostos de aroma utilizados em alimentos são 'naturais'. Diferentemente dos processos químicos, que requerem temperaturas e pressões extremas, as conversões microbianas ocorrem sob condições brandas e, em alguns exemplos, os produtos são formados estereosseletivamente ${ }^{3}$.

O limoneno, 4-isoprenil-1-metil-ciclo-hexeno, um monoterpeno monocíclico faz parte da estrutura de mais de 300 vegetais ${ }^{4}$. Os dois enantiômeros do limoneno são os mais abundantes monoterpenos na natureza. $S$-(-)-limoneno é principalmente encontrado em uma variedade de plantas e ervas como Mentha spp, enquanto $R$-(+)-limoneno é o componente majoritário dos óleos das cascas de limão e laranja e do óleo essencial de alcarávia, sendo a prevenção da desidratação e a inibição de crescimento microbiano suas funções naturais nos vegetais ${ }^{1}$.

No caso dos óleos essenciais dos cítricos em geral, o $R$-(+)limoneno é seu componente mais expressivo, atingindo concentrações de 90 a $96 \% 5$. Aproximadamente 50 mil t de $R$-(+)-limoneno são recuperadas ao ano como subproduto da indústria cítrica mundi$\mathrm{al}^{5,6}$. O limoneno é geralmente separado do óleo essencial obtido no suco de laranja pela sua baixa solubilidade em água, alta tendência à autoxidação e polimerização, e formação de "off-flavors", tornando-

*e-mail:mario@fea.unicamp.br se um subproduto industrial adequado para bioconversões a compostos de alto valor comercial ${ }^{6}$. Além disso, existem diversas aplicações para o limoneno, como solvente para resinas, síntese de outros compostos químicos, aplicações em borracha, tintas, agente dispersante para óleo, além da utilização na síntese química do mentol ${ }^{7}$.

A era entre 1945 e 1960 marcou o início da indústria de suco de laranja na Flórida, o que levou a um aumento na porcentagem de laranjas destinada ao suco concentrado de menos de 1 para $80 \%$. A conseqüente disponibilidade de grandes quantidades de $R-(+)-$ limoneno de baixo custo (US\$ 1-2/kg) interessou a químicos e biólogos. Isso se explica, principalmente, pelo fato de alguns compostos medicinais e de aroma possuírem fórmulas estruturais semelhantes ao limoneno, sugerindo grande potencial para a utilização industrial desse rejeito industrial ${ }^{8}$.

Como exemplo, pode-se citar alguns de seus derivados mais notáveis como os compostos oxigenados $\alpha$-terpineol, álcool perílico, carveol, carvona e mentol. Mentol e carvona são compostos de aroma extensivamente utilizados, sendo que o álcool perílico vem ganhando destaque crescente devido às comprovações relacionadas a seu poder de prevenção a doenças degenerativas. Portanto, a utilização de $R$-(+)-limoneno para síntese de compostos de aroma e compostos funcionais pode ser considerada promissora do ponto de vista econômico. Assim sendo, a biotransformação catalítica de $R$-(+)limoneno em compostos de aroma, como carvona e álcool perílico, foi considerada desde os anos 60 por duas vantagens principais: grandes regioespecificidade e enantioespecificidade enzimáticas, fazendo com que numerosos microrganismos e células de plantas fossem descritos como transformadores deste monoterpeno ${ }^{8}$.

Entretanto, a grande maioria dos estudos de biotransformação de monoterpenos descritos até o momento são apenas acadêmicos, sendo inviáveis do ponto de vista industrial, pois sua aplicação direta em escalas maiores esbarra nos baixos rendimentos devido à volatilidade do substrato e toxicidade do limoneno aos microrganismos em geral ${ }^{3}$.

\section{Problemas da biocatálise}

A toxicidade dos microrganismos ao precursor limoneno e a multiplicidade dos metabólitos originados da biotransformação do monoterpeno resultam em baixas concentrações dos produtos finais e intermediários, elevando os custos da recuperação dos compos- 
tos gerados. Adicionalmente, um longo tempo de fermentação é necessário para que os produtos se acumulem em grandes quantidades, o que contrasta diretamente com a necessidade de um curto tempo de fermentação, uma vez que o substrato monoterpênico (limoneno) possui altas instabilidade e volatilidade 9 .

\section{O baixo rendimento dos processos de biotransformação}

Os compostos de aroma estão freqüentemente presentes em baixas concentrações nos sistemas fermentativos, resultando em alto custo para os processos de recuperação (isso pode ser compensado pelo alto preço dos aromas naturais, de 10 a 100 vezes maiores que os sintéti$\cos )^{10}$. Muitos estudos revelam o efeito inibidor do limoneno em vários microrganismos. Além disso, alguns autores relatam que o limoneno diminui a velocidade do processo de fosforilação oxidativa nas células ${ }^{3}$. Log P é utilizado como medida estabelecida da toxicidade de microrganismos a solventes orgânicos imiscíveis em água. As toxicidades mais fortes foram observadas em valores de $\log \mathrm{P}$ entre 1 e 5 . Compostos como o limoneno (com $\log \mathrm{P}=4,83$ ) aumentam a fluidez das membranas dos fungos filamentosos, o que leva a permeabilidade não específica, perda de integridade celular, decréscimo de matéria seca e inativação da energia metabólica devido à dissipação da força próton motiva (gradiente eletroquímico de $\mathrm{H}^{+}$através da membrana) ${ }^{11}$. A alta fluidez da membrana pode prevenir a manutenção dos complexos entre enzima e membrana como, por ex., o complexo formado entre citocromo $\mathrm{P} 450$ monoxigenase e citocromo P-450 redutase dependente de NADPH, que está envolvido nas transformações oxidativas de terpenos, hidrocarbonetos policíclicos aromáticos, esteróides e outros compostos lipofílicos, promovidas por fungos ${ }^{11}$.

\section{Problemas relacionados à recuperação dos produtos da biotransformação}

"Downstream processing" significa isolamento, concentração e purificação de um produto. O sistema de destilação ou extração em batelada, padrão nas indústrias de biotecnologia, requer operações em grandes volumes. A volatilidade e baixa solubilidade em água de muitos compostos de aroma tornam sua recuperação difícil de ser realizada. Por outro lado, existe um limite superior para a concentração do produto final no meio de fermentação por causar inibição e toxicidade aos microrganismos ${ }^{10}$. Pelo fato de os produtos biotransformados encontrarem-se presentes em pequenas concentrações, esse processo torna-se custoso. Quatro razões sugerem a extração de bioaromas in situ utilizando avançadas técnicas de separação ${ }^{12}$ : perda de produtos por volatilização; instabilidade bioquímica do produto na presença das células; fenômeno de inibição e, concentração de produto não constante nas bateladas.

Há, portanto, a necessidade de desenvolvimento de técnicas mais específicas aplicáveis in loco e em condições de esterilidade. Aromas muito voláteis são os que mais necessitam desse tipo de tecnologia.

\section{ROTAS METABÓLICAS ENVOLVIDAS NA BIOTRANSFORMAÇÃO DO LIMONENO}

A introdução regioespecífica de grupos carbonilas ou hidroxilas através de reações químicas é difícil, devido às propriedades eletrônicas similares dos grupos metilas presentes nos carbonos 3 e 6 e nos carbonos 7 e 10 do limoneno ${ }^{11}$ (Figura 1). Conseqüentemente, a oxidação química clássica gera mistura de produtos. Um exemplo representativo é a oxidação alílica do limoneno utilizando dióxido de selênio que produz limonen-4ol, trans-carveol, cis-carveol, álcool perílico e limonen-10-ol. Entretanto, há uma exceção: limoneno pode ser convertido exclusivamente a carvona através da reação com cloreto de nitrosila.

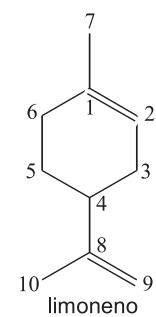

Figura 1. Estrutura do limoneno

Dessa forma, o processo biotecnológico apresenta a vantagem de ser regido por reações enzimáticas, as quais se diferenciam da síntese química por serem enantio e regioespecíficas. Por essa razão, a oxidação enzimática do limoneno foi primeiramente estudada nos anos 60 por Dhavalikar e Bhattacharyya ${ }^{13}$. Posteriormente a esse estudo, grande número de metabólitos foi isolado e identificado e vários microrganismos e células de plantas foram classificados como capazes de transformar o limoneno em compostos de interesse, demonstrando que o monoterpeno em questão é facilmente atacado pelo sistema enzimático de certos microrganismos. Entretanto, pouco sucesso tem sido alcançado na tentativa de converter os dados laboratoriais em processos industriais.

Os últimos cinco anos têm visto significativos progressos no campo da biotransformação de limoneno, especialmente no que se refere à regioespecificidade da biocatálise por microrganismos. Trabalhos recentes descrevem a hidroxilação das posições 3 (resultando em isopiperitenol), 6 (produzindo carveol e carvona) e 7 (álcool perílico, aldeído perílico e ácido perílico como produtos). Progressos consideráveis têm sido atingidos na caracterização de limonenohidroxilases de plantas e clonagem dos seus genes codificantes ${ }^{8}$.

Seis rotas principais de conversão do limoneno podem ser distinguidas (Figura 2): oxidação do substituinte metila a compostos perílicos; conversão da dupla ligação do anel ao diol correspondente; oxidação alílica a cis, trans carveóis e carvona; epoxidação da ligação dupla na unidade isoprenil a $\alpha$-terpineol; oxidação alílica a isopiperitenol e epoxidação da ligação 8,9 a limoneno-8,9-epóxido.

\section{Oxidação do substituinte metila a compostos perílicos}

Primordialmente, três substâncias de interesse industrial são resultantes do ataque da posição 7 do limoneno (1): álcool perílico (2), aldeído perílico (3) e ácido perílico (4). O composto (2) é de particular importância, uma vez que várias investigações têm relatado que essa substância, extraída de lavanda (Lavandula angustifolia), possui propriedades preventivas contra câncer de fígado, mama e pulmões ${ }^{3}$. Segundo ensaios in vivo, (1) e (4) têm demonstrado inibição da metástase em células de ratos $^{16}$.

Um vasto número de estudos tem estabelecido que alguns isoprenóides como (1), (2), além de $\gamma$-tocoferol, $\beta$-ionona e farnesol apresentam propriedades de inibição da formação de tumores. Isoprenóides têm se mostrado capazes de diminuir o crescimento de vasto número de tumores animais, incluindo células leucêmicas, melanomas, tumores pancreáticos e hepatomas. Ratos alimentados com $1 \%$ da dieta com (2) apresentaram uma taxa de regressão do tumor de $55 \%$. Nesse estudo, conclui-se que o monoterpeno (2) é um candidato excelente para tratamento terapêutico de câncer humano ${ }^{17}$. Recentemente, foi evidenciado o uso de (2) e seus derivados monoterpênicos (utilizados isoladamente ou em combinação com agentes imunodepressivos como ciclosporinaA e azatioprina) para tratamento de pacientes submetidos a transplante de órgãos ${ }^{18}$. Relata-se que esses compostos são capazes de promover uma redução no nível de rejeição.

Investigações relatam a biotransformação de (1) com obtenção 


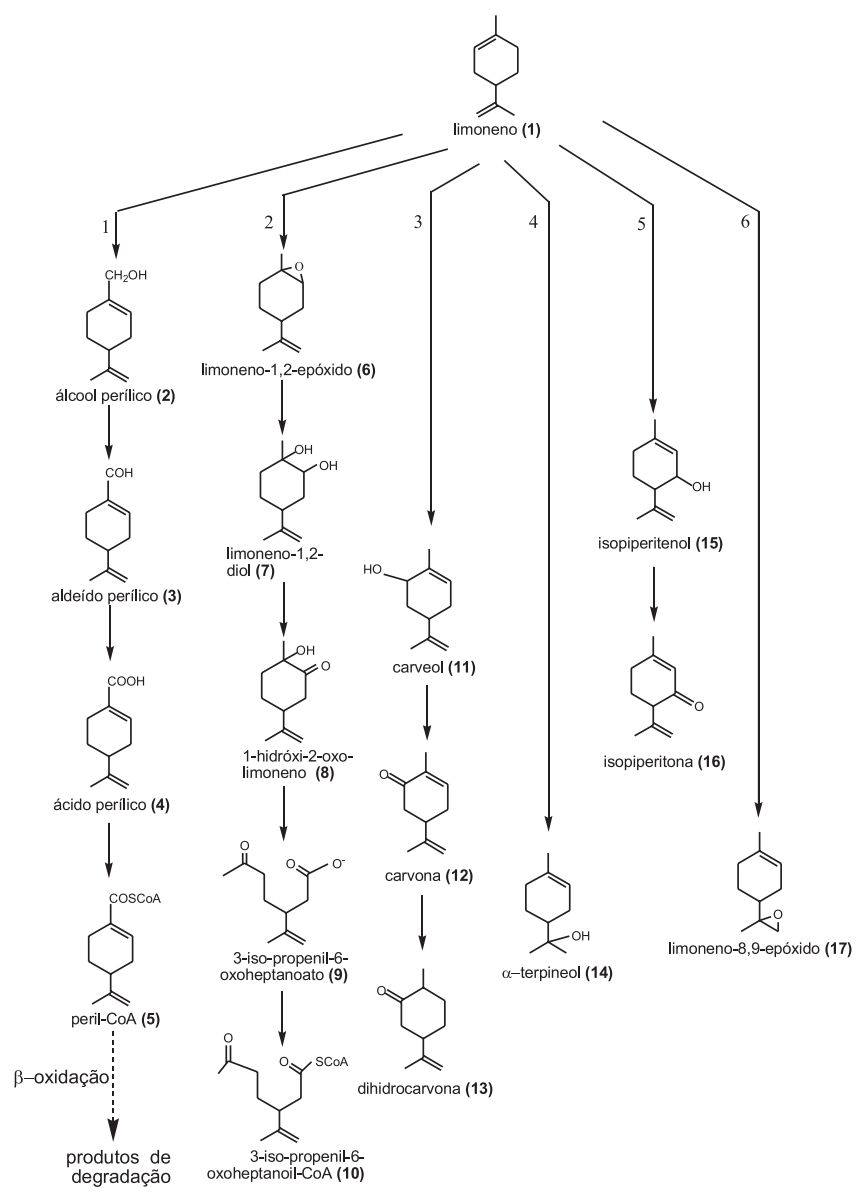

Figura 2. Principais rotas envolvidas na biotransformação do limoneno

dos compostos perílicos por linhagens de leveduras ${ }^{19}$, fungos filamentosos (Penicillium digitatum) e, principalmente, por bactérias ${ }^{3,9,13,20-22}$.

Uma estratégia comum para seleção de linhagens de bactérias com potencial biotransformador de (1) é a utilização de técnicas de enriquecimento de cultura usando o substrato como única fonte de carbono $^{9,13,20,21,23}$.

O primeiro relato de biotransformação de (1) a compostos perílicos foi realizado por Dhavalikar e Bhattacharyya. Os autores descreveram a biotransformação de $R-(+)-(1)$ por meio de uma linhagem de Pseudomonas isolada de uma amostra de solo. Relataram a formação de outros compostos de interesse industrial, como carveol (11), carvona (12) e diidrocarvona (13) ${ }^{13}$. Cadwallader et $a .^{20}$ selecionaram uma linhagem de Pseudomonas gladioli capaz de biotransformar (1) a (4) e $\alpha$-terpineol (14). A concentração de (4) atingiu 1861 ppm no quarto dia de contato com o substrato terpênico e posteriormente sofreu um rápido decréscimo, sendo que no sétimo dia não podia mais ser detectado ${ }^{19}$. Em 1992, Yoshiaki et al. relataram a biotransformação de $R$-(+) e $S$-(-)-(1), respectivamente, a $R$ (+)- e $S$-(-)-(2) por uma linhagem de Aspergillus cellulosae ${ }^{24}$.

Já uma linhagem de Bacillus stearothermaphilus BR388 isolada da casca de laranja foi capaz de metabolizar (1) como única fonte de carbono (mostrando resistência ao substrato, suportando concentração máxima de $0,15 \%$ do monoterpeno), mas degradou (1) mais eficazmente na presença de extrato de levedura. (2) foi o composto produzido em maior quantidade, atingindo concentração máxima de $200 \mathrm{mg} / \mathrm{L}^{21}$. Um fragmento cromossomal de 9,6 kb da mesma linhagem foi inserido em E. coli, a qual foi capaz de metabolizar (1) nos mesmos produtos obtidos com a linhagem bacilácea ${ }^{25}$. Em um estu- do posterior, o mesmo grupo inseriu um fragmento de 3,6 kb da mesma linhagem em E. coli, resultando na biotransformação do $R$ (+)-(1) a (2) e (12), sendo (12) formada pela ação de uma desidrogenase não específica da linhagem de $E$. coli $^{22}$. A produção de (4) em alta concentração ( $3 \mathrm{~g} / \mathrm{L})$ foi descrita por Speelmans et al. ${ }^{9}$. Linhagens identificadas como Pseudomonas putida possuem a capacidade de adaptar sua membrana pela conversão de ácidos graxos cis- para trans- na presença de solventes como tolueno e estireno. Linhagens resistentes a solventes são excelentes candidatos para realizar a conversão de (1), uma vez que se mostram mais resistentes ao acúmulo de terpenóides tóxicos. Os autores revelam que glicerol foi necessário como co-substrato para crescimento e produção de (4), sendo ótima a combinação de $150 \mathrm{mM}$ de (1) e $50 \mathrm{mM}$ de glicerol. $\mathrm{O}$ uso de amônia ou uréia como fonte de nitrogênio revelou-se como fator de grande importância à bioconversão. As condições de 30 a $34{ }^{\circ} \mathrm{C}$ e $\mathrm{pH}=7$, assim como a utilização de emulsificantes, foram determinantes para o acúmulo do produto de interesse, o qual não sofreu etapas de metabolização subseqüientes a outros compostos, apresentando-se quimicamente estável, sendo, ainda, o (4) o único composto resultante da conversão 9 .

Uma outra linhagem de Pseudomonas putida MTCC 1072 oxidou (1) a (2) e p-ment-1-eno-6,8-diol com rendimentos de 36 e 44\%, respectivamente, sendo que não foram observadas degradações subseqüentes. Os autores relatam que a linhagem é resistente a uma concentração de (1) de 0,2\% (v/v), sendo que na concentração de $0,5 \%$ (v/v) os rendimentos sofreram uma redução significativa. Relatam também que o $\mathrm{pH}$ tem forte influência na conversão, sendo $\mathrm{pH}=5,0$ o valor ótimo, observando-se ainda queda brusca na atividade a valores de $\mathrm{pH}=3,0$ e 7,03.

Trytek e Fiedurek ${ }^{26}$ relatam a biotransformação de (1) a (2) e (4) a partir de uma linhagem de fungo filamentoso psicrotrófico, Mortierella minutíssima 01, isolada de uma amostra de solos árticos. A linhagem foi selecionada por melhor se desenvolver em placas de Petri contendo ágar em contato com vapor de (1). A produção de outros compostos, como (11) e (12) além de óxido-de-limoneno, indica que a linhagem é capaz de atacar o monoterpeno em diferentes posições. Os autores relatam que a hidroxilação da posição C-6, gerando (11), parece ser favorecida a $30{ }^{\circ} \mathrm{C}$ em comparação a $15{ }^{\circ} \mathrm{C}$, a qual se mostrou mais eficiente para a hidroxilação da posição C-7, gerando (2). A linhagem mostrou resistência a concentrações de $0,8 \%$ (v/v) de (1), sendo que um aumento em sua concentração para 1,2\% gerou inibição. Os autores defendem que biotransformação a baixas temperaturas com microrganismos psicrotróficos pode ser vantajosa por um lado por evitar a evaporação do substrato, por outro, apresenta o empecilho do lento desenvolvimento da linhagem.

\section{Conversão da dupla ligação do anel ao diol correspondente}

Recentemente van der Werf et al. ${ }^{14}$ confirmaram a rota de degradação de (1) ao seu diol correspondente, através de estudos bioquímicos com uma linhagem de Rhodococcus erythropolis submetida a (1) como única fonte de carbono. Observou-se que a linhagem inicia seu ataque com a epoxidação da ligação dupla 1,2 do anel (através da limoneno-1,2-monoxigenase), sendo que a hidrólise de limoneno-1,2-epóxido (6) a limoneno-1,2-diol (7) foi catalisada por uma limoneno-1,2-epóxido-hidrolase muito ativa e indutível [enzima indutível é aquela expressa apenas em presença do seu substrato, no caso, o monoterpeno em estudo, (1)]. As degradações subseqüentes dão origem a 1-hidróxi-2-oxo-limoneno (8), que se rearranja espontaneamente a 3-iso-propenil-6oxoeptanoato (9) ${ }^{15}$. Ambos os enantiômeros de (1) foram degradados analogamente, mas as configurações estereoquímicas dos intermediários de $R$-(+) e $S$-(-)-(1) são opostas, sendo que as ativida- 
des das mesmas enzimas foram detectadas na biotransformação de ambos os enantiômeros, o que sugere que as enzimas envolvidas apresentaram enantio e estereoespecificidades ${ }^{14}$. Este foi o primeiro relato sobre microrganimos que metabolizam (1) por meio de uma rota iniciada pelo ataque de sua ligação dupla 1,2. Essa substância não possui aroma impactante, mas pode ser utilizada para sínteses posteriores.

Há relatos anteriores de ser (7) o produto de biotransformação majoritário em leveduras e fungos filamentosos e um produto minoritário obtido através de biotransformação com linhagens de bactérias ${ }^{14}$. Uma linhagem de Cladosporium sp também se mostrou capaz de atacar a ligação 1,2 de (1) resultando em cis- e transdiol (7) como produtos principais, gerando concentrações finais de 0,2 e 1,5 g/L, respectivamente, após 4 dias de fermentação. Abraham et $a l .{ }^{27}$ produziram o mesmo composto utilizando uma linhagem de fungo filamentoso, Corynespora cassiicola DSM 62475. Do ponto de vista da produtividade, esta foi uma das mais interessantes aproximações práticas relatadas até então: em um fermentador de $70 \mathrm{~L}, 1,3 \mathrm{~kg}$ de (1) foram transformados em $900 \mathrm{~g}$ de produto em 96 h de fermentação ${ }^{27}$. Um outro estudo de seleção com mais de 60 linhagens também resultou na formação de cis- e trans-diol (7) a partir de $R$-(+)- e $S$-(-)-(1), por uma linhagem de Corynespora cassiicola, com rendimentos de $50 \%$ aproximadamente ${ }^{28}$.

\section{Oxidação alílica a cis, trans carveóis e carvona}

A oxidação da posição 6 de (1) pode gerar substâncias de relevada importância industrial como (11) e (12). (12) ocorre nas formas $R-(+)$ e $S-(-)$ e seus isômeros diferem consideravelmente nas propriedades sensoriais. Eles ocorrem em altas porcentagens em grande número de óleos essenciais. $R-(+)-(12)$ é o componente principal do óleo de alcarávia (presente em concentrações de $60 \%$, aproximadamente), enquanto que $S$-(-)-(12) ocorre em óleo de hortelã, em uma concentração de 70 a $80 \%^{29}$. Ambos os isômeros são utilizados como compostos de aroma em alimentos e bebidas. $S$-()-(12) é produzida em maiores quantidades, sendo utilizada em produtos de higiene bucal ${ }^{30}$.

Monoterpenóides quirais são importantes para o balanceamento do bouquet de muitos óleos essenciais e aroma de frutas. Por ex., uma mistura de (-)-linalol, (-)-citronelol, (-)-cis-óxido de rosa, (-)mentol e $R-(+)-(\mathbf{1 2})$ é a base molecular para o aroma de óleo de Rosa Bulgária, um composto com potencial utilização pela indústria de aromas e fragrâncias ${ }^{30}$.

Além disso, (11) e (12) parecem atuar no organismo humano como antioxidantes e, segundo recentes investigações, encontramse em vários compostos que podem atuar como coadjuvantes para tratamento e prevenção do processo de envelhecimento ${ }^{31}$. O ataque da posição C-6 de (1) foi relatado primeiramente em 1966 pelo pioneiro grupo indiano, que obteve (11), (12) e (13) ${ }^{13}$. Foi estudada a transformação de (1) por linhagens de Penicillium digitatum e Penicillium italicum isolados de frutas cítricas. A biotransformação conduzida com a linhagem de $P$. italicum apresentou rendimento de $80 \%$ na conversão de (1), quando sua concentração inicial foi $0,5 \%(\mathrm{v} / \mathrm{v})$. Concentrações maiores que essa foram inibitórias. A biotransformação de (1) por $P$. italicum resultou em cis- e trans(11), (12), cis e trans-p-menta-2,8-dien-1-ol, p-menta-1,8-dien-1ol e $p$-menta-8-eno-1,2-diol ${ }^{32}$. Um estudo mais recente mostrou o potencial de um basidiomiceto, Pleurotus sapidus, ao transformar regioespecificamente $R-(+)-(\mathbf{1})$ em cis,trans-(11) e $R$-(+), $S$-(-)-(12) como produtos principais. O substrato foi adicionado com 2,5 dias de crescimento até o quarto dia, sendo a biotransformação estendida até 12 dias pela adição do substrato em fase gasosa. Os rendimentos foram aumentados com a realização do pré-cultivo em pre- sença de (1). Depois de 2 dias de fermentação, $97 \%$ do substrato se acumulou no micélio e $3 \%$ ficaram no meio de cultura. Em contrapartida, os produtos se acumularam em concentrações três a quatro vezes maiores no meio aquoso em relação ao micélio. Após 12 dias de cultivo, as concentrações de (11) e (12) atingiram valores ao redor de 70 e $30 \mathrm{mg} / \mathrm{L}$, respectivamente quando o substrato terpênico foi adicionado na forma gasosa. Os autores relataram que o pré-cultivo realizado em presença de (1) não aumentou a capacidade de crescimento do microrganismo, mas a taxa de biotransformação e as concentrações máximas dos produtos foram mais de duas vezes maiores para (11) e três a quatro vezes maiores para (12) comparando-se aos testes sem a pré-adaptação. A adaptação do microrganismo pode ser devida a dois fatores: adaptação geral do metabolismo e/ou indução das enzimas envolvidas pela adição do substrato ${ }^{11}$. Entretanto, até o momento, as enzimas de plantas têm demonstrado a maior regioespecificidade. A enzima limoneno-6-hidroxilase isolada do microssomo de uma espécie de Menta spp foi capaz de converter o $S$-(-)-(1) em (11) ${ }^{33-35}$. Outro exemplo é a oxidação de $R$-(+)-(1) às misturas racêmicas de (11) e (12) pelas espécies Solanum aviculare e Dioscorea deltoidea. Observou-se que as células de $S$. aviculare foram capazes de transformar 34\% do (1) adicionado em (12) (mistura racêmica). Apesar da alta regioespecificidade, observa-se que a atividade das células vegetais em geral ainda é insuficiente para uma aplicação de um processo em escala industrial ${ }^{36}$.

Uma linhagem de bactéria, Rhodococcus opacus PWD4, foi capaz de hidroxilar (1) exclusivamente na sua posição 6, gerando (+)-trans-(11) como único produto, com rendimento final de 94 a $97 \%$. Os pesquisadores realizaram o cultivo das células em presença de tolueno como única fonte de carbono e energia. A mesma linhagem desenvolvida em glicose como única fonte de carbono não foi capaz de biotransformar (1), sugerindo que uma das enzimas envolvidas na degradação do tolueno pode ser responsável pela biotransformação de (1). Os autores sugerem que uma possível candidata seja a tolueno-2,3-dioxigenase ${ }^{37}$.

\section{Epoxidação da ligação dupla na unidade isoprenil a $\alpha$ - terpineol}

O $\alpha$-terpineol (14) é um importante produto comercial. Pequenas quantidades do terpenóide são encontradas em muitos óleos essenciais (por ex., em coníferas e óleos de lavanda); enquanto que $\beta$-, $\gamma$ - e $\delta$-terpineol não ocorrem largamente na natureza. $S$-(-)-(14) ocorre na espécie Pinus palustris Mill., apresentando-se em concentração menor que $60 \%$ em seu óleo essencial. (S)-(-)(14) possui um odor caracteristicamente conífero, enquanto $(R)$ (+)-(14) tem aroma floral intenso, com "treshold" de $350 \mathrm{ppb}$. Apesar do (14) ocorrer em muitos óleos essenciais, como de "grape fruit", bergamota e lima, apenas pequenas quantidades são isoladas, por ex., por destilação fracionada de óleos de pinho. Esse composto possui aplicações importantes, sendo utilizado, por ex., em sabonetes e alguns cosméticos ${ }^{29}$.

Reconhecidamente, (14) é um interessante produto final da bioconversão de (1). Esse processo tem sido descrito utilizando-se uma grande variedade de microrganismos como catalisadores. O primeiro relato da obtenção de $R$-(+)-(14) por meio da biotransformação de $R$-(+)-(1) foi feito por Kraidman et al. em 1969. A transformação foi catalisada por uma linhagem de Cladosporium $\mathrm{sp}^{38}$. Desde 1985, vários autores têm relatado o relevante potencial de linhagens de Penicillium sp ao converter $R$-(+)-(1) em $R-(+)-(\mathbf{1 4})^{28,39-43}$. Tan et al. relataram que a linhagem utilizada demonstrou enantiosseletividade e enantioespecificidade ao converter a mistura racêmica de (1) a $R$ (+)-(14). A atividade aumentou mais de 12 vezes após indução atra- 
vés da adição seqüencial do substrato, o que proporcionou um rendimento de 3,2 g/L de (14) após 96 h de reação em escala laboratorial ${ }^{42}$. Levando-se em conta a indução enzimática, e outras características como inibição pelo agente quelante de ferro fenantrolina, pode-se concluir que o sistema enzimático citocromo P450-dependente envolvido na bioconversão se assemelha ao das bactérias, como por ex., da linhagem Pseudomonas sp., da qual diferentes monoxigenases citocromo P450-dependentes foram purificadas e caracterizadas ${ }^{6,44}$. Tan e Day utilizaram o micélio imobilizado (da mesma linhagem) em biorreator. Relataram que o leito se manteve ativo por pelo menos 14 dias. A produção de $R-(+)-(\mathbf{1 4})$ atingida foi de aproximadamente $13 \mathrm{mg} /(\mathrm{g}$ de leito)/dia, correspondendo a uma conversão molar do substrato maior que $45 \%$, quando o nível de oxigênio dissolvido foi de $50 \mu \mathrm{mol} / \mathrm{L}$. A avaliação econômica mostrou que a produtividade precisa ser aumentada para que o processo possa ser aplicável do ponto de vista industrial ${ }^{41}$. Os mesmos autores ainda avaliaram o efeito de 22 co-solventes orgânicos em células livres e imobilizadas. Com as imobilizadas, um aumento de 2 vezes na produção de (14) foi observado em sistema de micela reversa $(0,1 \%(\mathrm{v} / \mathrm{v}))$ de Tween 80 ou Triton 100-X). O alginato de cálcio é hidrofílico, enquanto que o substrato é hidrofóbico, promovendo, indubitavelmente, uma redução do contato com o substrato para as células imobilizadas. Já para células livres, o aumento na atividade foi de 2,2 e 2,4 vezes com $1,5 \%$ (v/v) de decanoato de etila e dioctilftalato, respectivamente ${ }^{42}$. Outros materiais utilizados para a imobilização de células, além do alginato de cálcio, são materiais celulósicos (como DEAE-celulose) e porosos (como alginatos, ágar, quitosana e ácido poli-galacturônico $)^{43}$.

O potencial da microextração em fase sólida (MEFS) foi reconhecido para seleção de linhagens biotransformadoras de (1) por um grupo belga. Demyttenaere et al. ${ }^{28}$ investigaram mais de 60 linhagens de fungos filamentosos, realizando uma otimização dos parâmetros de MEFS relevantes: tipo de fibra a ser utilizado, tempo de extração e temperatura. Os autores concluíram que as melhores condições de análise foram adsorção em fibra de polidimetilsiloxano revestida com divinil-benzeno/carboxeno (50/ $30 \mu \mathrm{m}$ ), à temperatura de $25^{\circ} \mathrm{C}$ por $30 \mathrm{~min}$. Deste trabalho destaca-se a nova e prática metodologia para seleção das linhagens, utilizando culturas de superfície desenvolvidas nos próprios frascos específicos para MEFS. As linhagens selecionadas foram investigadas posteriormente quanto a biotransformação em cultura submersa. Uma linhagem de $P$. digitatum isolada de uma amostra de poncã mostrou alta enantiosseletividade ao converter $93 \%$ de $R$ (+)-(1) em $R$-(+)-(14) em presença de etanol como co-solvente. O mesmo microrganismo foi capaz de transformar o $S$-(-)-(1), entretanto, apenas quantidades traço foram alcançadas ${ }^{44}$.

\section{Oxidação alílica a isopiperitenol e isopiperitona}

Os respectivos isômeros de isopiperitona (16) foram obtidos por meio da hidroxilação alílica e desidrogenação da posição C-3 de $R$ (+)- e $S$-(-)-(1) com uma linhagem de Aspergillus celulosae com rendimentos de 19 e $3 \%$, respectivamente, sendo que a (+)-piperitona foi apresentada como principal produto da biotransformação, que gerou também outros produtos após 7 dias de incubação a $30{ }^{\circ} \mathrm{C}^{24}$.

Em um trabalho posterior, uma linhagem de levedura identificada como Hormonema sp. foi capaz de transformar o $R-(+)-(\mathbf{1})$ em transisopiperitenol (15) em concentração de $0,5 \mathrm{~g} / \mathrm{L}$ após $12 \mathrm{~h}$ de incubação. Este foi o primeiro relato da obtenção biotecnológica de trans(15), o qual pode ser facilmente convertido a (-)-mentol por meio de uma hidrogenação. Infelizmente, os autores relataram pouca reprodutibilidade dos resultados, o que compromete a implantação de um processo industrial com o microrganismo. Atribui-se a falta de reprodutibilidade a mutações morfológicas evidenciadas por meio de variações da aparência, ao microscópio, e cor da cultura, que variava de preto a amarelo-esverdeado ${ }^{45}$.

De forma geral, os microrganismos oxidam (1) não especificamente, produzindo uma ampla variedade de metabólitos, levando a um grande número de compostos indesejados, embora haja algumas exceções. Entretanto, a conversão é sempre catalisada por enzimas catabólicas, que permitem que (1) seja utilizado como fonte de energia. Em plantas, enzimas de algumas espécies mostraram regioespecificidade ao atacar o $S$-(-)-(1) em sua posição C-3.

Em uma espécie de Mentha ssp (M.x piperita) a hidroxilação alílica na posição C-3 de $S$-(-)-(1) levou à formação de (-)-(15) e, posteriormente, a (-)-mentol ${ }^{35}$. O mesmo grupo demonstrou que a regioespecificidade das C-3 e C-6 limoneno-hidroxilases envolvidas na transformação de $S$-(-)-(1) em mentol e (12), respectivamente, é determinada pela substituição de um aminoácido, F363I, a qual converte C-6 em C-3 hidroxilase. Esses estudos sugerem uma possibilidade futura de modificar geneticamente e clonar o citocromo P450 de plantas para alterar a especificidade das hidroxilases quanto ao substrato e/ou produtos ${ }^{8}$.

Além disso, relata-se que os genes de Mentha spp responsáveis pela produção de limoneno-hidroxilases foram expressos com sucesso em Saccharomyces cerevisiae e Escherichia coli ${ }^{33}$.

\section{Epoxidação da ligação 8,9 a limoneno-8,9-epóxido}

O primeiro relato da obtenção de limoneno-8,9-epóxido (17) através da epoxidação de (1) nas posições 8 e 9 foi feito por van der Werf et al. ${ }^{46}$, que utilizaram uma linhagem de Xanthobacter sp. C20 isolada de uma amostra de sedimentos cujo crescimento ocorreu em cicloexano como única fonte de carbono. Aparentemente, uma monoxigenase indutível do citocromo P450 catalisa a hidroxilação do cicloexano (possivelmente uma enzima citocromo P450 dependente) e não hidroxila o anel cicloexênico do $R-(+)-(\mathbf{1})$, mas catalisa sua epoxidação, dando origem a $(4 R, 8 R)-(17)$ como único produto da reação, sendo relatada uma taxa de conversão de aproximadamente $100 \%$. $S$-(-)-(1) também foi convertido a uma mistura na proporção de 78:22 de $(4 S, 8 R)$ - e $(4 S, 8 S)-(\mathbf{1 7})$, com $100 \%$ de taxa de conversão. Relata-se a forte inibição pela formação de produtos, a qual não pôde ser minimizada por meio da utilização de co-solventes orgânicos ${ }^{46}$. (17) tem sido encontrado na fração volátil de muitos alimentos, incluindo poncã e gengibre ${ }^{47}$.

\section{CONCLUSÃO}

Apresentaram nesta revisão alguns dos principais avanços observados nos últimos anos com relação à biotransformação de (1) em compostos de interesse industrial, assim como a elucidação de algumas rotas metabólicas por meio de enzimas régio e estéreo específicas. A biotransformação com células inteiras apresenta reais vantagens econômicas se comparada aos processos com enzimas purificadas e, em alguns casos, as enzimas são mais estáveis dentro das células, estendendo a "vida" da biocatálise, além da adição de co-fatores não ser requerida, uma vez que já estão contidos nas mesmas. Os processos de transformação microbiana de terpenóides têm explorado a obtenção de produtos de interesse comercial ${ }^{3}$.

É evidente o progresso que a biotransformação de (1) sofreu na última década. Ratifica-se que a busca por novas biocatálises regioespecíficas teve sucesso por estabelecer rotas metabólicas diferentes das já conhecidas, o que acarretou na produção de novos compostos de aroma com aplicação industrial relevante, os quais podem ser considerados 'naturais', atendendo à exigência do mercado consumidor. 
Compostos de aroma produzidos por biotransformação tenderão a substituir os compostos de aroma obtidos sinteticamente em um futuro próximo. Em países europeus, essa transformação já está em curso. Isso se deve principalmente às vantagens que o processo de biotransformação oferece frente à síntese química, além da potencialidade das transformações microbianas em produzir compostos de aroma novos e com aplicações diversas na indústria, como demonstrado ao longo desta revisão.

Entretanto, algumas dificuldades precisam ser vencidas. Metodologias em biologia molecular são necessárias para otimizar as propriedades da biocatálise, como conferir maior estereosseletividade ou termoestabilidade, até mesmo uma diferente capacidade de atacar substratos diferentes.

Apesar de alguns relevantes avanços, a aplicação direta da biotransformação em escala industrial ainda esbarra em alguns empecilhos, como a expressão de enzimas régiosseletivas e estereosseletivas em altos níveis em linhagens hospedeiras seguras ("food-grade") e o desenvolvimento de técnicas de extração compatíveis com o apelo dos compostos de aroma originados do processo de biotransformação, considerados naturais.

Um dos desafios para o futuro é a expressão de oxigenases do citocromo P450 de plantas responsáveis pela síntese de diferentes enantiômeros e estereoisômeros de (2), (11) e (15) em linhagens hospedeiras, que permitam o aumento da escala, utilizando-se de produção em biorreatores.

Espera-se que a disponibilidade de oxigenases específicas, o rápido desenvolvimento de suas aplicações e o alto valor agregado dos produtos biotransformados a partir de (1) possibilitem bioprocessos industriais de alta escala nos próximos anos, para que seja possível atender à crescente exigência do mercado consumidor por produtos 'naturais' e de qualidade.

\section{AGRADECIMENTOS}

Ao CNPq (Conselho Nacional de Desenvolvimento Científico e Tecnológico) pelo apoio financeiro (Número do Processo 141601/ 2004-3).

\section{REFERÊNCIAS}

1. Demyttenaere, J.; Kimpe, N.; J. Mol. Catal. B: Enzym. 2001, 11, 265

2. Serra, S.; Fuganti, C.; Brenna, E.; Trends Biotechnol. 2005, 23, 193.

3. Chatterjee, T.; Bhattacharyya, D. K.; Appl. Microbiol. Biotechnol. 2001, $55,541$.

4. Burdock, G. A.; Fenaroli's Handbook of Flavour Ingredients, $3^{\text {rd }}$ ed., CRC: Boca Raton, 1995.

5. Nonino, E. A.; Perf. Flav. 1997, 22, 53.

6. Berger, R. G.; Krings, U.; Zorn, H. Em Food Flavour Technology; Taylor A. J., ed.; 2002, cap. 3.

7. http://www.abecitrus.com.br, acessada em Dezembro 2004.

8. Duetz, W. A.; Bouwmeester, H.; Beilen, J. B.; Witholt, B.; Appl. Microbiol. Biotechnol. 2003, 61, 269.

9. Speelmans, G.; Bijlsma, A.; Eggink, G.; Appl. Microbiol. Biochem. 1998, $33,538$.
10. Janssens, L.; De Pooter, H. L.; Schamp, N. M.; Vandamme, E. J.; Process Biochem. 1992, 27, 195.

11. Onken, J.; Berger, R. G.; J. Biotechnol. 1999, 69, 163.

12. Berger, R. G.; Aroma biotechnology, Berlin-Heidelberg: Springer-Verlag, 1995.

13. Dhavalikar, R. S.; Bhattacharyya, P. K.; Indian J. Biochem. 1966, 3, 144

14. van der Werf, M. J.; Swarts, H. J.; de Bont, J. A. M.; Appl. Environ. Microbiol. 1999, 65, 2092.

15. http://umbbd.ahc.umn.edu, acessada em Fevereiro 2006

16. Raphael, T. J.; Kuttan, G.; J. Experimet. Clin. Cancer Research 2002, 22 , 419.

17. Gould, M. N.; Crowell, P. L.; Elson, C. E.; Ren, Z.; US pat. WO9524895, 1995.

18. Imagawa, D. K.; Ming-Sing, S.; US pat. 6,133,324, 2000.

19. van Rensburg, E.; Moleleki, N.; van der Walt, J. P.; Botes P. J.; van Dyk, M. S.; Biotechnol. Lett. 1997, 19, 779.

20. Cadwallader, K. R.; Braddock, R. J.; Parish, M. E.; Higgins, D. P.; J. Food Sci. 1989, 54, 1241.

21. Chang, H. C.; Oriel, P.; J. Food Sci. 1994, 59, 660.

22. Cheong, T. K.; Oriel, P. J.; Appl. Biochem. Biotechnol. 2000, 84, 903.

23. Dhavalikar, R. S.; Rangachari, P. N.; Bhattacharyya, P. K.; Indian J. Biochem. 1966. 3,158

24. Noma, Y.; Yamasaki, S.; Asakawa, Y.; Phytochemistry 1992, 31, 2725.

25. Chang, H. C.; Cage, D. A.; Oriel. P.; J. Food Sci. 1995, 59, 660.

26. Trytek, M.; Fiedurek, J.; Biotechnol. Lett. 2005, 27,149.

27. Abraham, W. R.; Stumpf, B.; Kieslich, K.; Appl. Microbiol. Biotechnol. 1986, 24, 24.

28. Demyttenaere, J. C. R.; van Belleghem, K.; De Kimpe, N.; Phytochemistry 2001, 57, 199

29. Bauer, K.; Garbe, D.; Surburg, H.; Common Fragrance and Flavor Materials: Preparation, Properties and Uses, $2^{\text {nd }}$ ed., $\mathrm{VCH}$ Verlagsgesellschft mbH: Weinheim, 1990.

30. Ohloff, G.; Scent and Fragrances. The Fascination of Odors and their Chemical Perspectives, Springer-Verlag: Berlin and Heidelberg, 1994

31. Kawasaki, K.; Kokai T. K.; Jpn. JP2004018431, 2004 (CA 140:133439).

32. Bowen, E. R.; Florida State Horticultural Society, Florida, 1975, p. 304.

33. Haudenschild, C.; Schalk, M.; Croteau, R.; Arch. Biochem. Biophys. 2000, $379,127$.

34. Carter, O. A.; Peters, R.J.; Croteau, R.; Phytochemistry 2003, 64, 425.

35. Lupien, S.; Karp, F.; Wildung, M.; Croteau, R.; Arch. Biochem. Biophys. 1999, 368, 181.

36. Vanek, T.; Valterov, I. ; Vaisar, T.; Phytochemistry 1999, 50, 1347.

37. Duetz, W. A.; Fjallman, A. H. M.; Beilen, J. B.; Witholt, B.; Appl. Environ. Microbiol. 2001, 67, 2829.

38. Kraidman, G.; Mukherjee, B. B.; Hill, I. D.; Bacteriol. Proc. 1969, 69, 63.

39. Abraham, W. R.; Hoffman, H. M. R.; Kieslich, K.; Reng, H.; Stumpf, B.; CIBA Found. Symposium 111. Enzymes in Organic Synthesis, Pitman: Londres, 1990

40. Tan, Q.; Day, D. F.; Cadwallader, K. R.; Process Biochem. 1998, 33, 29.

41. Tan, Q.; Day, D. F.; Appl. Microbiol. Biotechnol. 1998, 49, 96

42. Tan, Q.; Day, D. F.; Process Biochem. 1998, 33, 755

43. Kourkoutas, Y.; Bekatorou, A.; Banat, I. M.; Marchant, R.; Koutinas, A. A.; Food Microbiol. 2004, 21, 377.

44. Adams, A.; Demyttenaere J. C. R.; De Kimpe, N.; Food Chem. 2003, 80, 525.

45. van Dyk, M. S.; van Rensburg, E.; Moleleki, N.; Biotechnol. Lett. 1998, 20, 431

46. van der Werf, M. J.; Keijzer, P. M.; van der Schaft, P. H.; J. Biotechnol. 2000, 84, 133.

47. Bell, S. G.; Sowden, R. J.; Wong, L-L.; Chem Commun. 2001, 7, 635. 